\title{
Editorial
}

\section{Role of Liver Resection for Hepatocellular Carcinoma with Vascular Invasion: Emerging Evidence from Western Countries}

\author{
Norihiro Kokudo ${ }^{a}$ Takashi Kokudo ${ }^{b}$ Kiyoshi Hasegawab \\ aDepartment of HPB Surgery, National Center for Global Health and Medicine, Tokyo, Japan; \\ ${ }^{b}$ Division of HPB Surgery, Department of Surgery, The University of Tokyo, Tokyo, Japan
}

\section{Keywords}

Hepatocellular carcinoma · Vascular invasion · Liver

resection - Guideline

\begin{abstract}
Patients with advanced hepatocellular carcinoma (HCC) with macrovascular invasion, that is, tumor thrombosis in the portal vein or hepatic vein, are generally considered not eligible for liver resection in Western countries, and only systemic therapy is recommended. However, there is a subgroup of patients who can survive long after surgical treatment despite having a very advanced stage of the disease. Some Asian surgical centers and a few Western surgical centers have been using surgery to treat BCLC stage C HCC as long as it is operable, and those centers have reported acceptable outcomes. In this issue of Liver Cancer, Govalan et al. report on the superiority of surgical resection over other treatments for patients with vascular invasion based on data from the National Cancer Database. This is a first report analyzing a large set of contemporary US cohort data, and its findings may catch the attention of many hepatologists in
\end{abstract}

karger@karger.com www.karger.com/lic

Karger

GOPEN ACCESS
(C) 2021 The Author(s)

Published by S. Karger AG, Basel

This is an Open Access article licensed under the Creative Commons Attribution-NonCommercial-4.0 International License (CC BY-NC) (http://www.karger.com/Services/OpenAccessLicense), applicable to the online version of the article only. Usage and distribution for commercial purposes requires written permission.
Western countries who are hesitant about sending eligible patients to surgeons. In this era of advanced systemic therapy using molecular targeted agents and immuno-check point inhibitors, a combination of promising systemic therapy and surgery may be a future path to improve survival for patients with this very advanced disease.

(C) 2021 The Author(s)

Published by S. Karger AG, Basel

Patients with advanced hepatocellular carcinoma (HCC) with macrovascular invasion, that is, tumor thrombosis in the portal vein (portal venous tumor thrombus) or hepatic vein (hepatic venous tumor thrombus), have been reported to have a poor prognosis $[1,2]$. Portal venous tumor thrombus can cause intrahepatic metastasis and increased portal pressure, leading to esophagogastric variceal hemorrhage. Hepatic venous tumor thrombus can extend into the inferior vena cava, leading to the formation of thrombi in the right atrium, intrapulmonary dissemination, pulmonary embolism, or even sudden death [3]. 
Table 1. Comparison of MST as a result of liver resection and nonsurgical treatment of HCC with vascular invasion

\begin{tabular}{|c|c|c|c|c|c|c|}
\hline \multirow[t]{2}{*}{ Lead author [ref.] } & \multirow[t]{2}{*}{ Inclusion criteria } & \multicolumn{2}{|c|}{ Liver resection } & \multicolumn{2}{|c|}{ Nonsurgical treatment } & \multirow[t]{2}{*}{$p$ value } \\
\hline & & patients, $n$ & MST, mo & patients, $n$ & MST, mo & \\
\hline Torzilli [6] & BCLC-C & 274 & $36^{*}$ & - & - & \\
\hline Kokudo [7] & $\begin{array}{l}\text { PVTT } \\
\text { After PSM }\end{array}$ & $\begin{array}{l}2,093 \\
1,058\end{array}$ & $\begin{array}{l}34.4 \\
29.4\end{array}$ & $\begin{array}{l}4,381 \\
1,058\end{array}$ & $\begin{array}{l}13.2 \\
18.8\end{array}$ & $\begin{array}{l}<0.001 \\
<0.001\end{array}$ \\
\hline Kokudo [8] & $\begin{array}{l}\text { HVTT } \\
\text { After PSM }\end{array}$ & $\begin{array}{l}540 \\
223\end{array}$ & $\begin{array}{l}53.6 \\
41.0\end{array}$ & $\begin{array}{l}481 \\
223\end{array}$ & $\begin{array}{l}19.0 \\
21.7\end{array}$ & $\begin{array}{r}<0.001 \\
0.023\end{array}$ \\
\hline Govalan [9] & $\begin{array}{l}\text { Vascular invasion } \\
\text { After PSM }\end{array}$ & $\begin{array}{l}325 \\
132\end{array}$ & $\begin{array}{l}21.4 \\
19^{*}\end{array}$ & $\begin{array}{r}4,268 \\
132\end{array}$ & $\begin{array}{l}8.1 \\
11^{*}\end{array}$ & $\begin{array}{l}<0.001 \\
<0.001\end{array}$ \\
\hline
\end{tabular}

MST, median survival time; PVTT, portal venous tumor thrombus; HVTT, hepatic venous tumor thrombus; PSM, propensity score matching. * Approximate value obtained from survival curves.

Patients with vascular invasion are generally considered not eligible for liver resection in Western countries, and only systemic therapy is recommended in the BCLC guidelines endorsed by the AASLD and EASL [4]. However, there is a subgroup of patients who can survive long after surgical treatment despite having a very advanced stage of the disease. Some Asian surgical centers and a few Western surgical centers have been using surgery to treat BCLC stage C HCC as long as it is operable, and those centers have reported acceptable outcomes $[5,6]$. There has been a consensus among liver surgeons in Asia on the use of liver resection for macrovascular invasion. Several studies, including those analyzing Japanese national data, have reported a better OS or DFS with liver resection than other nonsurgical treatments in this situation $[7,8]$. Randomized controlled trials may not be feasible in this situation because of tumor heterogeneity, how relatively rare that situation is, and the difficulty in obtaining informed consent for randomization. Precise analysis of a largescale cohort data using an appropriate statistical methodology, which includes propensity score matching (PSM), may be the next best option.

In this issue of Liver Cancer, Govalan et al. [9] report on the superiority of surgical resection over other treatments for patients with vascular invasion based on data from the National Cancer Database (NCDB). Surgical resection was associated with improved survival compared to systemic therapy (adjusted hazard ratio: 0.496, 95\% confidence interval: $0.426-0.578$ ), with a median survival of 21.4 months for the former versus 8.1 months for the latter. Superiority of surgical resection was observed in
PSM and inverse probability of treatment weighting adjusted analysis. We have to be cognizant of several limitations inherent in using the NCDB, including the unavailability of data on the extent of vascular invasion or the Child-Pugh classification, which are key prognostic variables for HCC. However, the study by Govalan et al. [9] analyzed a large set of contemporary US cohort data for the first time, and their finding may catch the attention of many hepatologists in Western countries who are hesitant about sending eligible patients to surgeons. Table 1 summarizes recent studies that used PSM to compare the long-term outcomes of liver resection and nonsurgical treatment of HCC with vascular invasion.

In this era of advanced systemic therapy using molecular targeted agents and immuno-check point inhibitors, a study recently reported on a very potent drug combination that can prolong survival for patients with vascular invasion [10]. A combination of promising systemic therapy and surgery may be a future path to improve survival for patients with this very advanced disease. A few studies on neoadjuvant systemic therapy before liver resection are underway or are being planned [11]. Current guidelines might be modified depending on the outcome of clinical trials of those approaches.

\section{Conflict of Interest Statement}

Norihiro Kokudo is an associate editor and Kiyoshi Hasegawa is an editorial board member of Liver Cancer. The authors have no conflicts of interest to declare. 


\section{Funding Sources}

The authors did not receive any funding.

\section{Author Contributions}

N. Kokudo, T. Kokudo, and K. Hasegawa conceived, wrote, and approved the final manuscript.

\section{References}

1 Thomas MB, Jaffe D, Choti MM, Belghiti J, Curley S, Fong Y, et al. Hepatocellular carcinoma: consensus recommendations of the national cancer institute clinical trials planning meeting. J Clin Oncol. 2010;28:39944005.

2 Kokudo T, Kokudo N. What liver surgeons have achieved in the recent decade for patients with hepatocellular carcinoma? Glob Health Med. 2020;2(5):265-8.

3 Liu J, Wang Y, Zhang D, Liu B, Ou Q. Comparison of survival and quality of life of hepatectomy and thrombectomy using total hepatic vascular exclusion and chemotherapy alone in patients with hepatocellular carcino$\mathrm{ma}$ and tumor thrombi in the inferior vena cava and hepatic vein. Eur J Gastroenterol Hepatol. 2012;24:186-94.

4 Ito $\mathrm{K}$, Takemura N, Inagaki F, Mihara F, Kokudo N. Difference in treatment algorithms for hepatocellular carcinoma between world's principal guidelines. Glob Health Med. 2020;2(5):282-91.

5 Ho MC, Hasegawa K, Chen XP, Nagano H, Lee YJ, Chau GY, et al. Surgery for intermediate and advanced hepatocellular carcinoma: a consensus report from the 5th Asia-Pacific primary liver cancer expert meeting (APPLE 2014). Liver Cancer. 2016;5:245-56.

6 Torzilli G, Belghiti J, Kokudo N, Takayama T, Capussotti L, Nuzzo G, et al. A snapshot of the effective indications and results of surgery for hepatocellular carcinoma in tertiary referral centers: is it adherent to the EASL/AASLD recommendations? An observational study of the HCC East-West study group. Ann Surg. 2013;257:929-37.

7 Kokudo T, Hasegawa K, Matsuyama Y, Takayama T, Izumi N, Kadoya M, et al. Survival benefit of liver resection for hepatocellular carcinoma associated with portal vein invasion. J Hepatol. 2016;65(5):938-43.
8 Kokudo T, Hasegawa K, Matsuyama Y, Takayama T, Izumi N, Kadoya M, et al. Liver resection for hepatocellular carcinoma associated with hepatic vein invasion: a Japanese nationwide survey. Hepatology. 2017;66(2): 510-7.

9 Govalan R, Lauzon M, Luu M, Ahn JC, Kosari $\mathrm{K}$, Todo T, et al. Comparison of surgical resection and systemic treatment for hepatocellular carcinoma with vascular invasion: national cancer database analysis. Liver Cancer. 2021.

10 Finn RS, Qin S, Ikeda M, Galle PR, Ducreux M, Kim TY, et al. Atezolizumab plus bevacizumab in unresectable hepatocellular carcinoma. N Engl J Med. 2020;382:1894-905.

11 Kaseb AO, Cao HST, Mohamed YI, Qayyum A, Vence LM, Blando JM, et al. Final results of a randomized, open label, perioperative phase II study evaluating nivolumab alone or nivolumab plus ipilimumab in patients with resectable HCC. J Clin Oncol. 2020;38:4599. 